\title{
Spanish traditional tomato. Effects of genotype, location and agronomic conditions on the nutritional quality and evaluation of consumer preferences
}

\author{
Esther Asensio $^{\mathrm{a}, *}$, Izarbe Sanvicente ${ }^{\mathrm{a}}$, Cristina Mallor ${ }^{\mathrm{b}}$, Susana Menal-Puey ${ }^{\mathrm{c}}$ \\ a Analytical Chemistry Department, Veterinary Faculty, University of Zaragoza, C/Miguel Servet, 177, 50013 Zaragoza, Spain \\ b Centro de Investigación y Tecnología Agroalimentaria de Aragón (CITA), Instituto Agroalimentario de Aragón - IA2 (CITA-Universidad de Zaragoza), Avda. Montañana 930, 50059 Zaragoza, \\ Spain \\ ${ }^{c}$ Animal Production and Food Science Department. Higher Polytechnic School, University of Zaragoza, Carretera de Cuarte s/n, 22071 Huesca, Spain
}

\section{ARTICLE INFO}

\section{Keywords:}

Bioactive antioxidant compounds

Nutritional attributes

Landraces

Greenhouse

Open field

Solanum lycopersicum L.

\begin{abstract}
A B S T R A C T
Traditional tomatoes are highly valued for their organoleptic quality and cultural links with a territory. At present, strong competition has put these crops at risk, and it is necessary to differentiate the local cultivars and improve their nutritional value.

This work focused on the nutritional study of four selected lines of a local tomato grown in two locations and in two agronomic conditions to nutritionally characterize the tomatoes and to study the effect of location and cultivation on nutritional parameters.

Data on nutritional characterization revealed significant effects of location and treatment in most compounds. Tomatoes grown in traditional areas showed a significantly higher concentration of some phenolic acids and beta-carotene. Lycopene contents were not location dependent. The open field test showed significant differences in all the components. Regarding the best nutritional genotypes, all the components were dependent on lines, and significant differences were confirmed between them.
\end{abstract}

\section{Introduction}

Recently, an increasing awareness of the importance of antioxidants in the diet has led to the expansion of "functional foods", nutraceutical markets, and the targeting of nutritional quality. As a consequence, the development of crop varieties with improved nutritional value has now become a priority. The composition of bioactive compounds of different fruits and vegetables is varied, both qualitatively and quantitatively. Moreover, the content of these substances can also be affected by the environmental and nutritional conditions of crops (agronomic conditions), as well as treatments made during the handling of fruits and vegetables at the post-harvest stage and processing to obtain derived foods. In addition, there are factors intrinsic to the plant itself (genetic), leading to the composition in these substances being different not only between different genera or species but also between varieties of the same species.

Tomato is an excellent source of nutrients and bioactive antioxidant compounds that are important for human health, including minerals, vitamins $\mathrm{C}$ and $\mathrm{E}$, beta-carotene, lycopene, flavonoids, organic acids, phenolics and chlorophyll (Navarro-González \& Periago, 2016;

\footnotetext{
Corresponding author.

Email addresses: estherac@unizar.es (E. Asensio); cmallor@cita-aragon.es (C. Mallor); smenal@unizar.es (S. Menal-pPuey)
}

Siddiqui, Ayala-Zavala, \& Dhua, 2015; Weisburger, 2002). The chemical composition of the tomato fruit depends on factors such as cultivar, maturity and the environmental conditions in which they are grown (Coyago-Cruz et al., 2018; Hernández-Suarez, 2011). The quality of food is the set of properties that make them accepted by consumers. These properties include those perceived by the senses (sensory qualities) as hygienic, nutritional and commercial properties. In tomato, these are determinants of quality, organoleptic properties, and the set of attributes of appearance, texture, smell, colour or taste that are perceived by the senses. Consumer choice is determined both by external parameters, such as shape, colour and absence of damage, and internal parameters, such as taste, aroma and texture parameters (Azodanlou, Darbellay, Luisier, Villettaz, \& Amado, 2003). Of all these attributes, flavour normally creates a greater impact on the consumer. The tomato flavour is directly related to its chemical composition (mainly sugars and organic acids), which varies depending on the type and degree of maturity of the fruit (Piombino et al., 2013).

Consumer complaints regarding the taste of modern commercial varieties have fostered the development of niche markets for heirloom, local or traditional varieties. These varieties have shown high levels of variation in agromorphological, genetic and organoleptic traits, but lit- 
tle is known about the variation in the concentrations of functional compounds (Cortes-Olmos, Leiva-Brondo, Rosello, Raigon, \& Cebolla-Cornejo, 2014). In this study, a Spanish traditional tomato variety, "Rosa de Barbastro", characterized by pink colour, large fruits (from 500 to $900 \mathrm{~g}$ ) and much appreciated flavour has been studied. It is characterized as an aromatic, fleshy, compact, and sweet tomato with little acidity and few seeds. Its wide acceptance in the market is due to its interior, with a characteristic taste and texture and a predominance of sweetness to acidity. Carravedo-Fantova (2006) considers is a great quality product.

In the present work, the nutritional quality (bioactive compounds) in the germplasm of four "Rosa de Barbastro" tomato lines located in two cultivated plots (different soil and climate) and under two agronomic conditions (open field and greenhouse) is studied. The hypotheses were that, in general, local tomato lines from the Agrifood Research and Technology Centre of Aragón (CITA), grown in Barbastro (traditional growing area) and in open field could shown best bioactive components that those grown in other location and in greenhouse, and that, in particular, the different genotypes could show a variable response under the experimental conditions. According to the sensorial quality it could be more appreciated by consumers versus other commercial varieties. The goal was to include these results in the breeding programme to increase the concentration of these nutritionally valuable compounds.

\section{Materials and methods}

\subsection{Chemicals}

Folin-Ciocalteu phenol reagent $(2 \mathrm{~N})$, beta-carotene (synthetic, $>95 \%$ ), lycopene (from tomato, >90\%), caffeic acid (>98\%), chlorogenic acid (titration, $>95 \%), p$-coumaric acid $(>98 \%)$, trans-ferulic acid (>99\%), DL-dithiothreitol (>98\%, HPLC), acetone, acetonitrile (HPLC grade), dichloromethane (HPLC grade), ethanol (HPLC grade), acetic acid and hexane (HPLC grade) were purchased from Sigma-Aldrich (Madrid, Spain). Methanol (HPLC grade), meta-phosphoric acid, sodium carbonate anhydrous, sodium chloride and sodium sulphate anhydrous were purchased from Panreac (Barcelona, Spain).

\subsection{Tomato samples}

In this study, four selected lines (Table 1) from the breeding programme (Centro de Investigación y Tecnología Agroalimentaria de Aragón, CITA) (Aguiar, Bruna, Llamazares, \& Mallor, 2014) of the tomato variety "Rosa de Barbastro" were grown in two locations: one in the area where this is traditionally cultivated, located in Barbastro (Huesca, Spain, long.: 42.018611/lat.: 0.130833/alt.: $365 \mathrm{~m}$ ), and the other in CITA experimental fields located in Montañana (Zaragoza, Spain, long.: 41.726944/lat.: -0.81 /alt.: $230 \mathrm{~m}$ ). In both locations, two assays were performed that differed in the production system: in the open field and under unheated plastic tunnel conditions (greenhouse).

Table 1

Selected lines of tomato "Rosa de Barbastro" from the breeding programme (CITA).

\begin{tabular}{lll}
\hline $\begin{array}{l}\text { Selected } \\
\text { line }\end{array}$ & Genetic code & Selected by \\
\hline Line 1 & BGHZ5204_13_01 & Good organoleptic qualities \\
Line 7 & BGHZ3576_47_07 & $\begin{array}{l}\text { High commercial production } \\
\text { Line 8 }\end{array}$ \\
Line 11 & BGHZ3576_59_08 & $\begin{array}{l}\text { High commercial production. } \\
\text { Good organoleptic evaluation, high } \\
\text { production values and optimum } \\
\text { evaluations of fruits in the laboratory }\end{array}$ \\
\hline
\end{tabular}

Hence, a total of four assays were carried out. Regionally recommended cultural practices, including fertilizer and plant protection measures, were followed. Fertilizers were applied in fertigation, through the drip irrigation system. Three soluble fertilizers were used, at the dose recommended by the manufacturer, according to the physiological stage of plant development. The NPK complex fertilizer 13-40-13 was applied from 20 May to 7 June, to favour rooting and to stimulate growth during the first stages of the crop cycle; the complex fertilizer 15-10-15 was applied from 10 June to 1 July to maintain the crop; and the complex fertilizer 15-5-30 from 3 July to harvest time, to favour flowering and ripening of the fruits.

For pest and disease control, the following products, at the dose recommended by the manufacturer, were applied: Propamocarb fosetilato (by fertigation, 2 May and 9 May) to control root and/or stem rot; Foli-stop (2 may and 9 may) to control fungus diseases; Bacillus thuringiensis kurstaki $24 \%$ (by spraying, 5 August) to control Heliothis armigera; and Azadiractin 1\% and Beuveria bassiana 2,3\% (by spraying, 5 August) to whitefly control. Moreover, during cultivation, the following biological control methods were used: blue and yellow sticky traps for monitoring thrips and whiteflies, respectively; funnel traps for monitoring and control Heliothis armigera; and traps with pheromones to catch adults of Tuta absoluta. Additionally, a control tomato from the Caramba variety was grown in both locations under greenhouse conditions.

In February 2014, seeds were sown in a cold greenhouse and grown until the 2-3 leaf stage to be transplanted in May 2014. A randomized block design, replicated three times, was adopted, with $6.3 \mathrm{~m}^{2}$ plots with a plant density of 3.2 plants $/ \mathrm{m}^{2}$. All fruits evaluated were harvested at the pink ripe stage. Before analysis, all tomato samples were ground and frozen and stored at $-20^{\circ} \mathrm{C}$ until analysis.

\subsection{Nutritional quality}

\subsubsection{Determination of phenolic acids}

All samples of tomato "Rosa de Barbastro" were crushed and frozen after collection. Vallverdú-Queralt, Jauregui, Di-Lecce, Andrés-Lacueva, and Lamuela-Raventos (2011) and Vallverdú-Queralt, Rinaldi-de-Alvarenga, Estruch, and Lamuela-Raventos (2013) developed a procedure for the extraction and isolation of phenolic compounds from samples of gazpacho and tomato juice. This procedure has been applied with slight modifications.

Tomato samples (12 g) were centrifuged for $15 \mathrm{~min}$ ( $4000 \mathrm{rpm})$. The supernatant was removed, and $2.5 \mathrm{~mL}$ of $70 \% \mathrm{MeOH}$ in Milli Q water was added to the pellet. The tubes were sonicated for $15 \mathrm{~min}$ and centrifuged for $15 \mathrm{~min}$. The supernatant was reserved, and the extraction was repeated with $2.5 \mathrm{~mL}$ of $70 \% \mathrm{MeOH}$. Both methanol extracts were mixed. The extract was filtered and analysed by HPLC-DAD (Haghi \& Hatami, 2010). The HPLC analysis was performed with HPLC Waters 600 equipment with a Photodiode Array Detector Waters 996 (Milford, Massachusetts, USA $)$ and Phenomenex $\mathrm{C}_{18}$ column $(250 \times 4.6 \mathrm{~mm}$ i.d., $5 \mu \mathrm{m})$. The column was maintained at room temperature, and elution was carried out with a linear gradient. The mobile phase was $4 \%(\mathrm{v} /$ v) tetrahydrofuran in acetonitrile and $0.4 \%$ phosphoric acid in water (35:65) at a flow rate of $1 \mathrm{~mL} / \mathrm{min}$. The injection volume of all samples was $50 \mu \mathrm{L}$, and each sample was analysed in triplicate. The spectral data of signals from the DAD detector were collected during the entire run in the range of $240-400 \mathrm{~nm}$.

The analytes were identified by matching the retention times and spectral characteristics against those of standards. The linear range of quantification of phenolic acids (caffeic acid, chlorogenic acid, p-coumaric acid and trans-ferulic acid) was prepared from 0.5 to $50.0 \mu \mathrm{g} / \mathrm{g}$ in methanol. 


\subsubsection{Determination of total phenolic content}

The total phenolic content was measured on the methanolic extract obtained for the determination of the polyphenols in the tomato samples using the Folin-Ciocalteu colourimetric method (Kaur et al., 2013) with slight modifications. First, $0.1 \mathrm{~mL}$ of the methanol extract was placed in a glass tube and $0.5 \mathrm{~mL}$ of Folin-Ciocalteu reagent and $2.9 \mathrm{~mL}$ of distilled water were added. The tube was shaken vigorously for $30 \mathrm{~s}$ and incubated in an ultrasonic bath for $5 \mathrm{~min}$. Next, $2 \mathrm{~mL}$ of $20 \%$ sodium carbonate was added, mixed and then allowed to react at room temperature for $30 \mathrm{~min}$ in the dark. The absorbance was measured at $760 \mathrm{~nm}$ on a UNICAM UV/Vis Spectrometer UV2 (England). Gallic acid was used as an external standard, and the linear range of quantification was 0.039-0.268 mg GAE/mL.

\subsubsection{Determination of carotenoids}

Carotenoids (lycopene and beta-carotene) were extracted according to a previously optimized methodology based on the methods described by Martínez-Valverde, Periago, Provan, and Chesson (2002); Sánchez-Moreno, Plaza, De-Ancos, and Cano (2003, 2006) and Cucu, Huvaere, Van-Den-Bergh, Vinkx, and Van-Loco (2012).

Briefly, triplicates of each tomato sample $(7 \mathrm{~g})$ were weighed into an amber $50 \mathrm{~mL}$ beaker, and $20 \mathrm{~mL}$ of a mixture of hexane/acetone/ ethanol $(2: 1: 1, \mathrm{v} / \mathrm{v} / \mathrm{v})$ was added to solubilize the carotenoids. Samples were shaken for $25 \mathrm{~min}$ in an ice bath. The extract was added to a $100 \mathrm{~mL}$ flask, and $50 \mathrm{~mL}$ of $10 \% \mathrm{NaCl}$ solution was added and shaken for $5 \mathrm{~min}$. The organic and aqueous layers were separated. The organic layer was washed with $2 \mathrm{~mL}$ of hexane/acetone/ethanol (2:1:1). The organic layers were combined and dried over anhydrous sodium sulphate. The final extract was evaporated to dryness, and the residue was dissolved in $1 \mathrm{~mL}$ of dichloromethane. The HPLC analysis was performed with HPLC Waters 600 equipment with a Photodiode Array Detector Waters 996 (Milford, Massachusetts, USA) and Phenomenex $\mathrm{C}_{18}$ column $(250 \times 4.6 \mathrm{~mm}$ i.d., $5 \mu \mathrm{m})$. The column was maintained at room temperature, and elution was carried out with a linear gradient. The mobile phase was acetonitrile/methanol (0.05 M ammonium acetate)/ dichloromethane $(65: 20: 15)$ containing $0.1 \%$ BHT at a flow rate of $2 \mathrm{~mL} / \mathrm{min}$. The injection volume of all samples was $20 \mu \mathrm{L}$. A UV-visible photodiode array detector was set at $470 \mathrm{~nm}$, and chromatographic data and UV-visible spectra were collected. Identification of the carotenoids was carried out by HPLC by comparing the retention time and UV-visible absorption spectrum with those of the standards (lycopene and beta-carotene), and the linear range of quantification was $10-1,100 \mu \mathrm{g} /$ $\mathrm{g}$ and $4.0-90.0 \mu \mathrm{g} / \mathrm{g}$, respectively.

\subsubsection{Determination of ascorbic acid and vitamin $C$}

Ascorbic acid and total vitamin C (ascorbic acid plus dehydroascorbic acid) were determined by HPLC-UV/Vis. The procedure employed to determine total vitamin $\mathrm{C}$ was the reduction of dehydroascorbic acid to ascorbic acid, using DL-dithiothreitol as a reductant reagent, according to a modification in the procedure of Sánchez-Mata, Cámara-Hurtado, Díez-Marques, and Torija-Isasa, (2000) and Verde-Méndez et al. (2011).

Forty millilitres of tomato juice were homogenized with $25 \mathrm{~mL}$ of extraction solution ( $3 \%$ meta-phosphoric acid $+8 \%$ acetic acid). The resulting mixture was centrifuged, filtered and adjusted to $25 \mathrm{~mL}$ with distilled water. Samples were filtered through a $0.45 \mu \mathrm{m}$ membrane filter, and triplicates of each extract were analysed by HPLC. The HPLC analysis was performed with HPLC Detector, HP 1050 Variable Wavelength detector, UV/VIS Model 79854A (Japan) and Kingsorb $\mathrm{C}_{18}$ column $(250 \mathrm{~mm} \times 4.6 \mathrm{~mm} \times 5 \mu \mathrm{m})$. Elution was carried out with a linear gradient. The mobile phase was $0.01 \%$ sulphuric acid $(\mathrm{pH}=2.5-2.6)$ at a flow rate of $0.5 \mathrm{~mL} / \mathrm{min}$. The injection volume of all samples was $20 \mu \mathrm{L}$. A UV-visible detector was set at $245 \mathrm{~nm}$. Ascorbic acid was used as a standard, and the linear range of quantification was $10.0-80.0 \mathrm{mg} / \mathrm{L}$. The results were expressed as $\mathrm{mg}$ ascorbic acid/100 mL tomato juice.

For the analysis of vitamin $\mathrm{C}$, an aliquot $(0.5 \mathrm{~mL})$ of the mixture was taken to react with $1.5 \mathrm{~mL}$ of a solution of $20 \mathrm{mg} / \mathrm{mL}$ DL-dithiothreitol for $2 \mathrm{~h}$ at room temperature in the dark. During this time, the reduction of dehydroascorbic acid to ascorbic acid occurred. Samples were filtered through a $0.45 \mu \mathrm{m}$ membrane filter, and triplicates of each extract were analysed by HPLC. The results were expressed as mg total vitamin C/ $100 \mathrm{~mL}$ tomato juice.

\subsection{Organoleptic quality}

To carry out the analysis of the organoleptic quality of the tomato variety "Rosa de Barbastro", BGHZ5204_13_01 (Line 1) was selected and compared with two commercial varieties available at the supermarket: Clothilde and Caniles. Analyses of sensory attributes of tomato fruits were made by consumers according a hedonic evaluation test. Fifty consumers evaluated the products for first impressions using check-all-that-apply (CATA) questions for sensory product characterization. The hedonic evaluation test asked consumers to rate their preference with a structures scale with five points, from 1 (I dislike extremely) to 5 (I like very much) and included descriptors for aroma (smell intensity), taste (intensity and sweet), and firmness (peel hardness and texture). In addition, they were asked to give an overall appreciation of tomatoes (Azodanlou et al., 2003). For the sensory analysis a laboratory was set up according to the international standard EN ISO 8589:2007, whole fruits were presented one by one on a plate identified by the sample number, and consumers were placed separately to avoid influences.

\subsection{Statistical analysis}

The data were subjected to a discriminant analysis procedure in SPSS (release 15.0) to identify significant treatment effects and interactions: the agronomic parameters (selected lines, location and production system) were set as independent variables and the contents of nutritional compounds (phenolic acids, total phenolic acid, carotenoids, ascorbic acid and vitamin C) as dependent variables. Previously, to compare quantitative variable means, the distribution of data was studied by the Kolmogorov-Smirnov test. A normal distribution was assumed when the $p$-value was not significant $(p>0.05)$.

Data comparisons between different location and production systems (categorical variables with two possible values) were undertaken by Student's $t$-test and between different selected lines (categorical variable with more than two values) by one-way analysis of variance (ANOVA). For non-parametric tests, Mann-Whitney $\mathrm{U}$ tests and Kruskal-Wallis $\mathrm{H}$ Tests were used ( $p$-value $<0.05$ was considered statistically significant). If the ANOVA test showed an overall statistically significant difference between group means $(p<0.05)$, a post hoc test (Bonferroni Test) was run to confirm which specific groups differed.

\section{Results and discussion}

\subsection{Phenolic acid levels}

Several studies have investigated the phenolic acid levels in raw tomatoes of different contents (García-Valverde, Navarro-González, García-Alonso, \& Periago, 2013; Hallmann, Lipowski, Marszałek, \& Rembiałkowska, 2013; Jacob, García-Alonso, Ros, \& Periago, 2010; Martínez-Valverde et al., 2002; Navarro-González \& Periago, 2016; Raffo, La Malfa, Fogliano, Maiani, \& Quaglia, 2006; Slimestad \& Verheul, 2009; Vallverdú-Queralt, Jauregui, Medina-Remon, \& Lamuela-Raventos, 2012). The concentrations of phenolic acids and to- 
tal phenolic contents reported here (Table 2) are in line with data from the literature, although the comparison is often hard because of the great influence of agronomic factors such as varieties and harvest time.

In the case of chlorogenic, ferulic and $p$-coumaric acid, the concentration ranges (9.5-37.3; 0.2-3.1 and $2.3-8.9 \mathrm{mg} / \mathrm{kg} \mathrm{FW}$, respectively) found in the tomato "Rosa de Barbastro" are within the expected values for this type of tomato. Chlorogenic acid was found in greater concentrations in all cases. In the case of caffeic acid levels, the values $(1.1-12.1 \mathrm{mg} / \mathrm{kg} \mathrm{FW})$ are greater than those found in other varieties of tomato studied, especially when grown in an open field. The values of total phenols present in the tomato "Rosa de Barbastro" are within the range reported in the literature (59.6-210.0 mg GAE/kg FW).

Comparing the results shown in Table 2, in the Barbastro and Montañana locations, it can be seen that quantified phenolic acid levels are higher when grown in an open field than when grown in a greenhouse. The data obtained for the control variety Caramba show intermediate values compared to the four lines of tomato "Rosa de Barbastro" grown in a greenhouse. These results are in accordance with studies carried out by San-José, Sánchez-Mata, Cámara, \& Prohens, 2014 where they found that the environment plays a major role in determining the composition of eggplant fruits, and that large differences in composition may exist among seasons, even with the same cultivation system (open field or greenhouse).

\subsection{Carotenoids levels}

Lycopene and beta-carotene levels are presented in Table 3 and expressed as $\mathrm{mg} / \mathrm{kg}$ FW. Lycopene ranged from 29.03 to $64.95 \mathrm{mg} / \mathrm{kg}$ $\mathrm{FW}$, and beta-carotene ranged from 1.37 to $6.41 \mathrm{mg} / \mathrm{kg} \mathrm{FW}$. The reported concentrations of lycopene and beta-carotene in tomato "Rosa de Barbastro" are in line with data from the literature (Campos, Chaves, De-Azeredo, Mata, \& Pinheiro-Santana, 2010; Erba et al., 2013; Guil-Guerrero \& Rebolloso-Fuentes, 2009; Hallmann et al., 2013; Kaur et al., 2013). It can be seen that in the Barbastro location, the lycopene content is higher when grown in the greenhouse than in the open field. In the Montañana location, the opposite occurs: the lycopene content in the open field is higher. The high intensity of light favours the content of carotenoids, in general, and especially that of lycopene (Dumas, Dadomo, Di Lucca, \& Grolier, 2003; Toor, Savage, \& Lister, 2006; Zapata, Gerard, Davies, \& Schvab, 2007), suggesting that the synthesis of lycopene is severely inhibited by exposure to intense solar radiation. Thus, it is expected that open field tomatoes may have lower concentrations of this lycopene (depending on the cultivar and climate).

Table 2

Levels of phenolic acids and total phenolic content, expressed as mg/kg FW and mg GAE/kg FW, in relation to agronomic parameters.

\begin{tabular}{|c|c|c|c|c|c|c|c|}
\hline Location & $\begin{array}{l}\text { Selected } \\
\text { line }\end{array}$ & $\begin{array}{l}\text { Production } \\
\text { system }\end{array}$ & $\begin{array}{l}\text { Chlorogenic } \\
\text { acid }\end{array}$ & Caffeic acid & Ferulic acid & $p$-coumaric acid & $\begin{array}{l}\text { Total phenolic } \\
\text { content }\end{array}$ \\
\hline \multirow[t]{9}{*}{ Barbastro } & \multirow[t]{2}{*}{ Line 1} & open field & $14.85 \pm 3.22$ & $8.30 \pm 1.99$ & $3.11 \pm 1.23$ & $3.69 \pm 0.77$ & $163.72 \pm 38.37$ \\
\hline & & greenhouse & $9.54 \pm 1.68$ & $4.65 \pm 1.08$ & $2.53 \pm 1.22$ & $3.32 \pm 1.18$ & $92.00 \pm 10.85$ \\
\hline & \multirow[t]{2}{*}{ Line 7} & open field & $18.14 \pm 3.44$ & $9.89 \pm 2.29$ & $2.12 \pm 0.54$ & $8.91 \pm 3.08$ & $144.70 \pm 12.74$ \\
\hline & & greenhouse & $13.16 \pm 4.97$ & $5.06 \pm 2.06$ & $0.24 \pm 0.18$ & $5.67 \pm 1.47$ & $86.62 \pm 13.74$ \\
\hline & \multirow[t]{2}{*}{ Line 8} & open field & $22.35 \pm 2.43$ & $12.03 \pm 2.54$ & $1.37 \pm 0.64$ & $6.02 \pm 2.39$ & $152.25 \pm 34.57$ \\
\hline & & greenhouse & $19.26 \pm 5.27$ & $8.15 \pm 3.76$ & $0.46 \pm 0.04$ & $6.81 \pm 3.00$ & $120.82 \pm 11.63$ \\
\hline & \multirow[t]{2}{*}{ Line 11} & open field & $21.20 \pm 4.40$ & $9.61 \pm 1.62$ & $1.86 \pm 0.14$ & $6.91 \pm 1.62$ & $131.92 \pm 17.11$ \\
\hline & & greenhouse & $18.88 \pm 4.38$ & $6.92 \pm 1.93$ & $0.59 \pm 0.06$ & $7.31 \pm 1.83$ & $102.31 \pm 9.00$ \\
\hline & Caramba & greenhouse & $16.66 \pm 2.59$ & $4.45 \pm 1.19$ & $2.27 \pm 0.35$ & ND & $91.93 \pm 9.71$ \\
\hline \multirow[t]{9}{*}{ Montañana } & \multirow[t]{2}{*}{ Line 1} & open field & $37.26 \pm 2.44$ & $10.74 \pm 2.51$ & $2.50 \pm 0.69$ & $6.75 \pm 1.55$ & $175.42 \pm 18.00$ \\
\hline & & greenhouse & $5.89 \pm 0.93$ & $1.11 \pm 0.22$ & $0.76 \pm 0.06$ & $2.84 \pm 0.10$ & $95.73 \pm 7.02$ \\
\hline & \multirow[t]{2}{*}{ Line 7} & open field & $26.59 \pm 8.33$ & $6.72 \pm 2.02$ & $0.57 \pm 0.03$ & $8.06 \pm 3.87$ & $126.64 \pm 21.98$ \\
\hline & & greenhouse & $23.02 \pm 2.30$ & $2.98 \pm 0.20$ & $0.71 \pm 0.04$ & $3.82 \pm 0.94$ & $76.31 \pm 10.29$ \\
\hline & \multirow[t]{2}{*}{ Line 8} & open field & $21.64 \pm 3.38$ & $2.94 \pm 0.33$ & $0.55 \pm 0.03$ & $6.12 \pm 2.39$ & $123.61 \pm 4.40$ \\
\hline & & greenhouse & $10.96 \pm 1.99$ & $1.16 \pm 0.24$ & $0.50 \pm 0.03$ & $6.16 \pm 1.12$ & $84.15 \pm 20.07$ \\
\hline & \multirow[t]{2}{*}{ Line 11} & open field & $25.77 \pm 2.88$ & $1.72 \pm 0.16$ & $0.20 \pm 0.01$ & $7.50 \pm 0.89$ & $142.29 \pm 30.25$ \\
\hline & & greenhouse & $23.02 \pm 4.44$ & $4.70 \pm 1.64$ & $0.35 \pm 0.07$ & $2.31 \pm 0.40$ & $121.33 \pm 12.00$ \\
\hline & Caramba & greenhouse & $15.28 \pm 2.16$ & $3.07 \pm 0.77$ & $1.50 \pm 0.24$ & ND & $66.71 \pm 8.36$ \\
\hline
\end{tabular}

$\mathrm{ND}=$ Not detected, Mean $\pm \mathrm{SD}$.

Table 3

Levels of lycopene and beta-carotene, expressed as $\mathrm{mg} / \mathrm{kg} \mathrm{FW}$, in relation to agronomic parameters.

\begin{tabular}{|c|c|c|c|c|}
\hline Location & Selected line & Production system & Lycopene & Beta-carotene \\
\hline \multirow[t]{9}{*}{ Barbastro } & Line 1 & open field & $56.66 \pm 7.08$ & $6.41 \pm 1.29$ \\
\hline & & greenhouse & $32.69 \pm 2.13$ & $3.40 \pm 0.56$ \\
\hline & Line 7 & open field & $29.03 \pm 6.32$ & $3.91 \pm 0.79$ \\
\hline & & greenhouse & $35.04 \pm 2.67$ & $2.12 \pm 0.22$ \\
\hline & Line 8 & open field & $47.60 \pm 8.18$ & $4.44 \pm 0.61$ \\
\hline & & greenhouse & $54.05 \pm 9.24$ & $2.82 \pm 0.82$ \\
\hline & Line 11 & open field & $36.44 \pm 4.21$ & $4.37 \pm 0.71$ \\
\hline & & greenhouse & $52.47 \pm 7.24$ & $2.94 \pm 0.48$ \\
\hline & Caramba & greenhouse & $35.34 \pm 13.01$ & $4.09 \pm 1.15$ \\
\hline \multirow[t]{9}{*}{ Montañana } & Line 1 & open field & $60.80 \pm 0.32$ & $4.57 \pm 0.24$ \\
\hline & & greenhouse & $43.00 \pm 2.06$ & $2.04 \pm 0.17$ \\
\hline & Line 7 & open field & $55.79 \pm 3.83$ & $3.91 \pm 0.60$ \\
\hline & & greenhouse & $37.12 \pm 2.36$ & $1.37 \pm 0.22$ \\
\hline & Line 8 & open field & $54.35 \pm 5.66$ & $2.85 \pm 0.39$ \\
\hline & & greenhouse & $64.95 \pm 3.79$ & $2.80 \pm 0.07$ \\
\hline & Line 11 & open field & $58.96 \pm 5.75$ & $2.77 \pm 0.11$ \\
\hline & & greenhouse & $37.37 \pm 12.69$ & $1.37 \pm 0.21$ \\
\hline & Caramba & greenhouse & $21.91 \pm 0.19$ & $2.24 \pm 0.06$ \\
\hline
\end{tabular}




\subsection{Ascorbic acid and vitamin $C$}

The levels of ascorbic acid and vitamin C found in the present study (Table 4) are consistent with some data reported in the literature (Anza, Riga, \& Garbisu, 2006; Moraru, Logendra, Lee, \& Janes, 2004) but lower than others (Mohammed, Smit, Pawelzik, Keutgen, \& Horneburg, 2012). When comparing the results of ascorbic acid and vitamin C, it is observed that in the locality of Barbastro, the quantities obtained in cultivation in the open field or greenhouse are similar, whereas in the locality of Montañana, the amount is much greater when cultivated in the open field.

\subsection{Sensory preferences}

The subjects were asked to rate the following sensory attributes: smell intensity, sweetness, peel hardness, texture and overall appreciation and the results are depicted as a spider-web-graphic (Fig. 1). The best overall appreciation was for the "Rosa de Barbastro" variety; consumers valued fruits of the Caniles and Clothilde cultivars 11.5\% and $15.4 \%$ lower, respectively, with statistically significant differences $(p<0.05)$. The intensity of taste and smell of the tomato "Rosa de Barbastro" was stronger than the others; nevertheless, it resulted in less sweetness than the Clothilde variety.

\subsection{Statistical study}

Three qualitative variables (location, production system and selected line) and nine quantitative variables (chlorogenic, caffeic, ferulic and $p$-coumaric acids, total phenolic content, lycopene, beta-carotene, ascorbic acid and vitamin C) were selected. Two explanatory factors (F1 and F2) were associated with each of the quantitative variables (location-F1-F2, production system-F1-F2 and selected line-F1-F2). A distribution was obtained in three clusters: cluster 1 (ascorbic acid, vitamin $\mathrm{C}$ and lycopene), cluster 2 (beta-carotene and ferulic acid) and cluster 3 (chlorogenic, caffeic, $p$-coumaric acid and total phenolic content), showing a grouping by affinity/chemical composition in this study. Fig. 2a-c show the grouping of the data obtained according to location, production system and selected line.

\subsubsection{Location study}

The study of the data distribution for the location variable showed normality for chlorogenic acid, p-coumaric acid, total phenolic content, lycopene, beta-carotene and ascorbic acid $(p>0.05)$; nevertheless, caffeic acid, ferulic acid and vitamin $C$ data were non-parametric $(p<0.05)$ (Table 5).

When data were associated with location variables (Table 6), higher concentrations of caffeic acid $(p<0.05)$, ferulic acid $(p<0.05)$, $p$-coumaric acid, total phenolic content and beta-carotene $(p<0.05)$ were observed in tomatoes grown in Barbastro. In contrast, tomatoes grown in Montañana showed significantly higher concentrations of chlorogenic acid, ascorbic acid and vitamin C $(p<0.05)$.

\subsubsection{Production system study}

When data were associated with the production system, chlorogenic acid and total phenolic content showed a normal distribution in greenhouse, nevertheless, in open field, only caffeic acid, $p$-cumaric acid and total phenolic content showed normality (Table 5).

Table 4

Levels of ascorbic acid and vitamin C, expressed as $\mathrm{mg} / \mathrm{kg} \mathrm{FW}$, in relation to agronomic parameters.

\begin{tabular}{|c|c|c|c|c|}
\hline Location & Selected line & Production system & Ascorbic acid & Vitamin C \\
\hline \multirow[t]{8}{*}{ Barbastro } & \multirow[t]{2}{*}{ Line 1} & open field & $25.39 \pm 10.38$ & $61.62 \pm 7.20$ \\
\hline & & greenhouse & $23.57 \pm 5.49$ & $61.54 \pm 4.29$ \\
\hline & \multirow[t]{2}{*}{ Line 7} & open field & $15.56 \pm 0.42$ & $48.63 \pm 6.21$ \\
\hline & & greenhouse & $18.78 \pm 3.89$ & $48.86 \pm 1.18$ \\
\hline & \multirow[t]{2}{*}{ Line 8} & open field & $65.77 \pm 6.41$ & $108.12 \pm 4.23$ \\
\hline & & greenhouse & $25.19 \pm 8.07$ & $63.42 \pm 3.04$ \\
\hline & \multirow[t]{2}{*}{ Line 11} & open field & $24.69 \pm 4.67$ & $57.25 \pm 8.60$ \\
\hline & & greenhouse & $32.96 \pm 1.58$ & $71.73 \pm 5.12$ \\
\hline \multirow[t]{8}{*}{ Montañana } & \multirow[t]{2}{*}{ Line 1} & open field & $63.44 \pm 6.42$ & $121.35 \pm 1.73$ \\
\hline & & greenhouse & $31.99 \pm 6.47$ & $33.42 \pm 3.21$ \\
\hline & \multirow[t]{2}{*}{ Line 7} & open field & $76.69 \pm 0.98$ & $126.63 \pm 0.48$ \\
\hline & & greenhouse & $27.38 \pm 0.89$ & $71.49 \pm 5.70$ \\
\hline & \multirow[t]{2}{*}{ Line 8} & open field & $47.26 \pm 4.16$ & $89.83 \pm 3.54$ \\
\hline & & greenhouse & $47.99 \pm 3.49$ & $59.96 \pm 2.53$ \\
\hline & \multirow[t]{2}{*}{ Line 11} & open field & $77.48 \pm 4.27$ & $128.59 \pm 4.00$ \\
\hline & & greenhouse & $28.93 \pm 0.99$ & $53.48 \pm 1.09$ \\
\hline
\end{tabular}

Mean $\pm \mathrm{SD}$
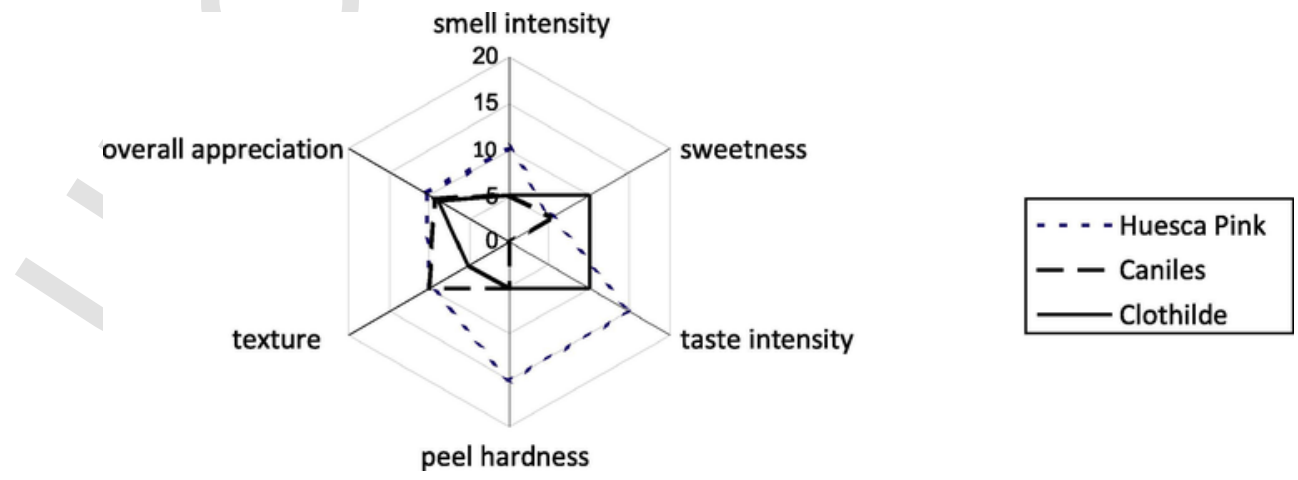

Fig. 1. Analysis of the three tomato cultivars (data length is proportional to the acceptability of the attribute). 

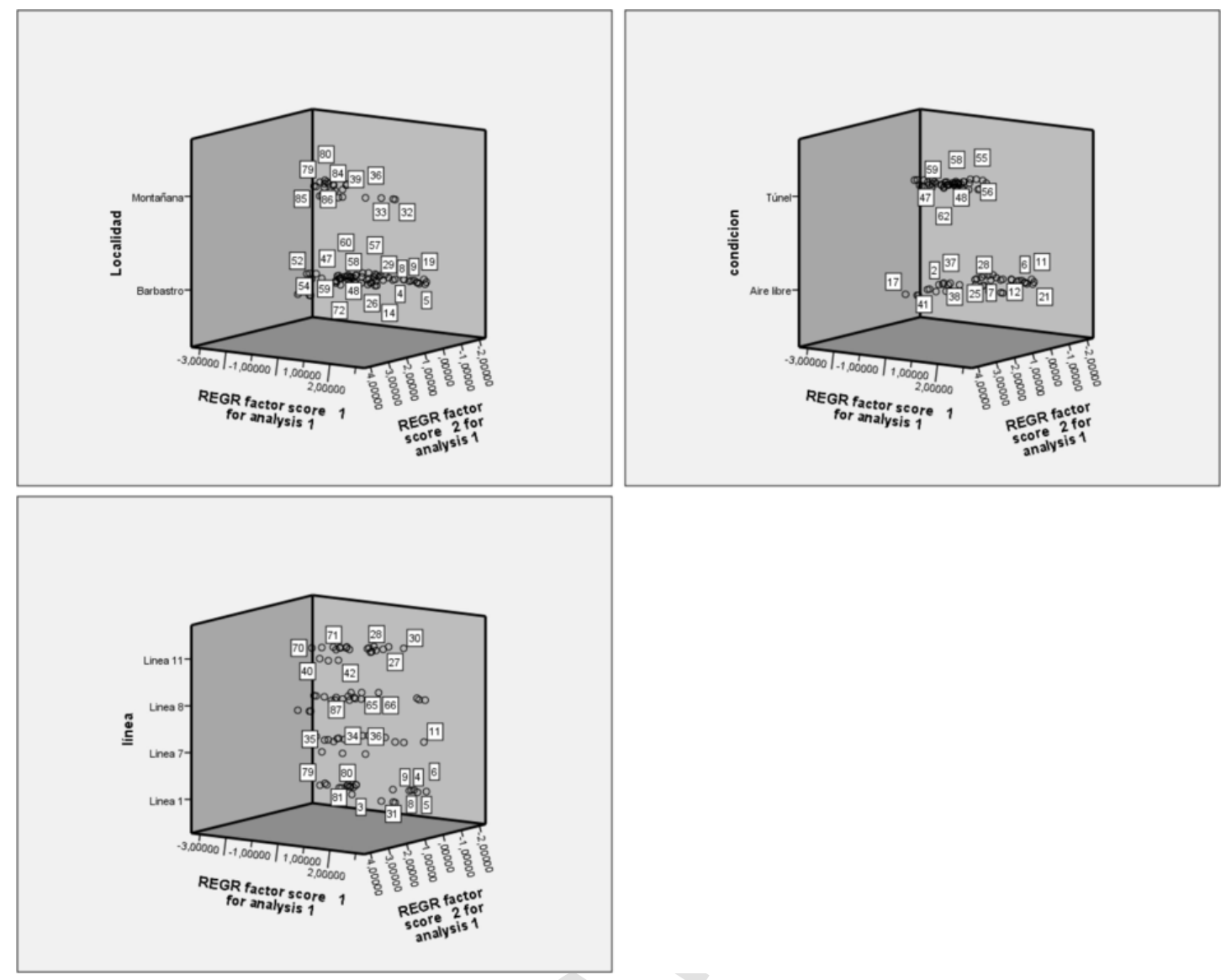

Fig. 2. a, b and c Grouping of the data obtained according to location-F1-F2, production system-F1-F2 and selected line-F1-F2.

Table 5

Kolmogorov-Smirnov test. Study of data distribution ( $p$ value).

\begin{tabular}{|c|c|c|c|c|c|c|c|c|}
\hline \multirow[t]{2}{*}{ Component } & \multicolumn{2}{|l|}{ Location } & \multicolumn{2}{|c|}{ Production system } & \multicolumn{4}{|l|}{ Lines } \\
\hline & Barbastro & Montañana & Greenhouse & Open field & 1 & 7 & 8 & 11 \\
\hline Chlorogenic acid & 0.200 & 0.200 & 0.200 & 0.038 & 0.005 & 0.002 & 0.002 & 0.200 \\
\hline Caffeic acid & 0.003 & 0.004 & 0.019 & 0.200 & 0.042 & 0.002 & 0.002 & 0.200 \\
\hline Ferulic acid & 0.001 & $<0.001$ & $<0.001$ & 0.039 & 0.200 & 0.001 & 0.035 & 0.007 \\
\hline Cumaric acid & 0.200 & 0.200 & 0.017 & 0.073 & 0.200 & 0.046 & 0.200 & 0.032 \\
\hline Total Phenolic content & 0.187 & 0.200 & 0.200 & 0.200 & 0.002 & 0.002 & 0.200 & 0.200 \\
\hline Lycopene & 0.200 & 0.070 & 0.005 & 0.002 & 0.200 & 0.200 & 0.200 & 0.149 \\
\hline Beta-carotene & 0.068 & 0.200 & 0.200 & 0.011 & 0.200 & 0.062 & 0.200 & 0.200 \\
\hline Ascorbic acid & 0.090 & 0.153 & 0.200 & 0.018 & 0.045 & $<0.001$ & $<0.001$ & $<0.001$ \\
\hline Vitamin C & $<0.001$ & 0.009 & 0.200 & 0.018 & 0.017 & 0.046 & 0.004 & $<0.001$ \\
\hline
\end{tabular}

The concentrations of chlorogenic acid, caffeic acid, ferulic acid, total phenolic content, lycopene, beta-carotene, ascorbic acid and vitamin C were higher in tomatoes grown in open field versus greenhouse, with statistically significant differences in chlorogenic acid, total phenolic content, caffeic acid, ferulic acid, beta-carotene, ascorbic acid and vitamin C $(p<0.05)$ (Table 6).

\subsubsection{Selected lines study}

The study of the distribution of quantitative variables showed normality in lycopene and beta-carotene data for the selected lines variable. The distribution of the other variables was non-parametric $(p<0.05)$ (Table 5).

The ANOVA test for parametric data (lycopene and beta-carotene) showed significant differences between lines, but the interaction contrast (Bonferroni test) confirmed that they occurred between
BGHZ3576_59_08 (Line 8) and Caramba, and selected line differences were not observed. Nevertheless, the post hoc test confirmed beta-carotene differences between lines, BGHZ5204_13_01 (Line 1) with BGHZ3576_47_07 (Line 7) and BGHZ3576_69_11 (Line 11). It is important to select genotypes.

For non-parametric data (chlorogenic acid, caffeic acid, ferulic acid, total phenolic content, ascorbic acid and vitamin C), the Kruskal-Wallis test showed significant differences between lines, and the post hoc tests confirmed that these differences occurred between pairs: Line 8 with Line 7 for ascorbic acid and vitamin C data, Line 11 with Line 1 for chlorogenic acid data and Line 1 with Line 7 , Line 1 with Line 8 and Line 1 with Line 11 for ferulic acid data. The other differences were due to Caramba pairs (control tomato).

Line 8 had the highest concentration of caffeic acid, lycopene, ascorbic acid and vitamin $\mathrm{C}$, with statistically significant differences. 
Table 6

Association of data for location, production system and lines variables. Mean \pm SD and $p$ value.

\begin{tabular}{|c|c|c|c|c|c|c|c|c|c|}
\hline Variable & Chlorogenic acid & Caffeic acid & Ferulic acid & $p$-cumaric acid & Total phenolic content & Lycopene & Betacarotene & Ascorbic acid & Vitamin C \\
\hline Barbastro & $17.17 \pm 4.33$ & $8.08 \pm 2.49$ & $1.54 \pm 1.05$ & $6.08 \pm 1.86$ & $124.29 \pm 28.71$ & $42.99 \pm 10.87$ & $3.80 \pm 1.32$ & $28.99 \pm 15.71$ & $65.15 \pm 18.97$ \\
\hline Montañana & $21.77 \pm 9.65$ & $4.00 \pm 3.32$ & $0.77 \pm 0.72$ & $5.45 \pm 2.17$ & $118.19 \pm 32.38$ & $51.54 \pm 10.88$ & $2.71 \pm 1.13$ & $50.15 \pm 20.49$ & $85.59 \pm 36.72$ \\
\hline$p$ (location) & 0.014 & $<0.001$ & 0.002 & 0.408 & 0.654 & 0.254 & 0.001 & $<0.001$ & 0.022 \\
\hline Open field & $23.48 \pm 6.74$ & $7.74 \pm 3.71$ & $1.54 \pm 1.04$ & $6.74 \pm 1.57$ & $145.07 \pm 18.13$ & $49.95 \pm 11.48$ & $4.15 \pm 1.14$ & $49.53 \pm 24.88$ & $92.75 \pm 33.10$ \\
\hline Greenhouse & $15.46 \pm 6.46$ & $4.34 \pm 2.52$ & $0.77 \pm 0.73$ & $4.78 \pm 1.93$ & $97.41 \pm 16.53$ & $44.58 \pm 11.40$ & $2,36 \pm 0.75$ & $29.59 \pm 8.72$ & $57,99 \pm 12.67$ \\
\hline$p$ (production) & $<0.001$ & $<0.001$ & 0.003 & 0.134 & $<0.001$ & 0.239 & $<0.001$ & $<0.001$ & $<0.001$ \\
\hline Line 1 & $16.88 \pm 14.07$ & $6.20 \pm 4.22$ & $2.23 \pm 1.02$ & $4.15 \pm 1.76$ & $131.72 \pm 43.99$ & $48.29 \pm 12.88$ & $4.11 \pm 1.85$ & $36.09 \pm 18.58$ & $69.48 \pm 37.03$ \\
\hline Line 7 & $20.23 \pm 5.85$ & $6.16 \pm 2.92$ & $0.91 \pm 0.83$ & $6.62 \pm 2.31$ & $108.56 \pm 32.43$ & $39.24 \pm 11.55$ & $2.83 \pm 1.29$ & $34.60 \pm 28.49$ & $73.90 \pm 36.75$ \\
\hline Line 8 & $18.55 \pm 5.23$ & $8.07 \pm 4.96$ & $0.72 \pm 0.43$ & $6.28 \pm 0.36$ & $120.20 \pm 27.92$ & $55.23 \pm 7.18$ & $3.23 \pm 0.81$ & $46.55 \pm 16.61$ & $80.33 \pm 22.83$ \\
\hline Line 11 & $22.21 \pm 2.91$ & $5.73 \pm 3.35$ & $0.75 \pm 0.75$ & $6.00 \pm 2.48$ & $124.46 \pm 17.07$ & $46.31 \pm 11.18$ & $2.86 \pm 1.23$ & $42.09 \pm 23.67$ & $79.74 \pm 33.43$ \\
\hline$p$ (lines) & 0.014 & 0.245 & $<0.001$ & $<0.001$ & 0.005 & 0.003 & $<0.001$ & $<0.001$ & 0.027 \\
\hline
\end{tabular}


Line 1 differed significantly in total phenolic content, ferulic acid and beta-carotene and Line 11 in chlorogenic acid (Table 6).

After grouping agronomic conditions, Line 8 significantly showed the best nutritional results when it was grown in a greenhouse, with the highest content of caffeic acid, lycopene, ascorbic acid, vitamin $\mathrm{C}$ and total phenolic content. In the open field, this line showed similar results in caffeic acid, vitamin $\mathrm{C}$ and ascorbic acid, but Line 1 presented the highest phenolic content and lycopene content.

\section{Conclusions}

In conclusion, the present study confirms that quality of tomato "Rosa of Barbastro" could be significantly modified with the agronomic conditions. According to the hypotheses, tomatoes grown in open field showed significant higher concentrations in all the components analyzed and in some phenolic acids and beta-carotene content when they were grown in traditional areas. However, behaviour was different to expected in ascorbic acid, vitamin $\mathrm{C}$, and chlorogenic acid.

Although hypothesis supposed a possible influence of light in lycopene synthesis, data were not location and condition dependent when they were grouped by variables.

This study demonstrated a genotype-by-environmental interaction between tomato lines and experimental conditions, allowing for the selection of the line with the best potential and better nutritional quality in each condition. Line 8 and Line 11 showed good nutritional behaviour in the open field and greenhouse, and Line 1 was a good option when it was cultivated in the greenhouse. They were all promising for a breeding programme.

This results confirm that an appropriate breeding program that includes phytochemical contents can produce cultivars with improvement in nutritional parameters.

Although only a consumer preferences analysis of one of these promising lines (BGHZ5204_13_01) was made, it corroborated the good overall appreciation of consumers versus other varieties of tomato. It could be possible to incorporate the organoleptic analysis in the phenotyping of lines into the selection programmes to achieve lines with a good nutritive and sensorial quality.

\section{Acknowledgements}

The authors would like to thank our stakeholders "Sociedad Cooperativa Limitada Agrícola de Barbastro" and "Asociación de Hortelanos y Amigos de la Huerta del Alto Aragón" for their participation and involvement in these works.

The authors would like to thank the Diputación de Huesca (Spain), Development and Localization section for the research fellowships (Félix de Azara, 2014) and thank the Centre of Studies of Somontano in Barbastro for the financial support.

The field assays carry out with the tomato "Rosa de Barbastro" has been co-financed by the European Union (EAFRD) and the Government of Aragon (Rural Development Program for Aragon 2007-2013)

The authors are grateful for the collaboration received from the Government of Aragon: Research groups T10, A01 and A16.

\section{References}

Aguiar, M., Bruna, P., Llamazares, A., Mallor, C., 2014. Evaluación de material vegetal seleccionado de Tomate Rosa de Barbastro (Solanum lycopersicum L.). Actas de Horticultura 69, 201-202

Anza, M., Riga, P., Garbisu, C., 2006. Effects of variety and growth season on the organoleptic and nutritional quality of hydroponically grown tomato. Journal of Food Quality 29 (1), 16-37. https://doi.org/10.1111/j.1745-4557.2006.00053.x.

Azodanlou, R., Darbellay, C., Luisier, J.L., Villettaz, J.C., Amado, R., 2003. Development of a model for quality assessment of tomatoes and apricots. LWT - Food Science and Technology 36 (2), 223-233. https://doi.org/10.1016/S0023-6438(02)00204-9.

Campos, F.M., Chaves, J.B.P., De-Azeredo, R.M., Mata, G.M., Pinheiro-Santana, H.M., 2010. Adequate handling conditions to preserve vitamin $\mathrm{C}$ and carotenoids in toma- toes. Journal of Food Quality 33 (SUPPL. 1), 230-245. https://doi.org/10.1111/j. 1745-4557.2010.00314.x.

Carravedo-Fantova, M. (2006). Variedades autóctonas de tomates de Aragón. Zaragoza, España: Centro de Investigación de Tecnología Agroalimentaria de Aragón (CITA) Gobierno de Aragón, España.

Cortes-Olmos, C., Leiva-Brondo, M., Rosello, J., Raigon, M.D., Cebolla-Cornejo, J., 2014 The role of traditional varieties of tomato as sources of functional compounds. Journal of the Science of Food and Agriculture 94 (14), 2888-2904. https://doi.org/10.1002/ jsfa.6629.

Coyago-Cruz, E., Corell, M., Moriana, A., Hernanz, D., Benítez-González, A.M., Stinco, C.M., Meléndez-Martínez, A.J., 2018. Antioxidants (carotenoids and phenolics) profile of cherry tomatoes as influenced by deficit irrigation, ripening and cluster. Food Chemistry 240 (August 2017), 870-884. https://doi.org/10.1016/j.foodchem.2017. 08.028 .

Cucu, T., Huvaere, K., Van-Den-Bergh, M.A., Vinkx, C., Van-Loco, J., 2012. A simple and fast HPLC method to determine lycopene in foods. Food Analytical Methods 5 (5), 1221-1228. https://doi.org/10.1007/s12161-011-9354-6.

Dumas, Y., Dadomo, M., Di Lucca, G., Grolier, P., 2003. Effects of environmental factors and agricultural techniques on antioxidant content of tomatoes. Journal of the Science of Food and Agriculture 83 (5), 369-382. https://doi.org/10.1002/jsfa.1370.

Erba, D., Casiraghi, M.C., Ribas-Agusti, A., Cáceres, R., Marfa, O., Castellari, M., 2013. Nutritional value of tomatoes (Solanum lycopersicum L.) grown in greenhouse by different agronomic techniques. Journal of Food Composition and Analysis 31 (2), 245-251. https://doi.org/10.1016/j.jfca.2013.05.014.

García-Valverde, V., Navarro-González, I., García-Alonso, J., Periago, M.J., 2013. Antioxidant bioactive compounds in selected industrial processing and fresh consumption tomato cultivars. Food and Bioprocess Technology 6 (2), 391-402. https://doi.org/ 10.1007/s11947-011-0687-3.

Guil-Guerrero, J.L., Rebolloso-Fuentes, M.M., 2009. Nutrient composition and antioxidant activity of eight tomato (Lycopersicon esculentum) varieties. Journal of Food Composition and Analysis 22 (2), 123-129. https://doi.org/10.1016/j.jfca.2008.10.012.

Haghi, G., Hatami, A., 2010. Simultaneous quantification of flavonoids and phenolic acids in plant materials by a newly developed isocratic high-performance liquid chromatography approach. Journal of Agricultural and Food Chemistry 58 (20), 10812-10816. https://doi.org/10.1021/jf102175x.

Hallmann, E., Lipowski, J., Marszałek, K., Rembiałkowska, E., 2013. The seasonal variation in bioactive compounds content in juice from organic and non-organic tomatoes. Plant Foods for Human Nutrition 68 (2), 171-176. https://doi.org/10.1007/ s11130-013-0352-2.

Hernández-Suarez, M., 2011. Estudio de la variación estacional del sabor del tomate. Universidad de Salamanca, España.

Jacob, K., García-Alonso, F.J., Ros, G., Periago, M.J., 2010. Stability of carotenoids, phenolic compounds, ascorbic acid and antioxidant capacity of tomatoes during therma processing. Archivos Latinoamericanos de Nutrición 60 (2), 192-198.

Kaur, C., Walia, S., Nagal, S., Walia, S., Singh, J., Singh, B.B., Sarika, 2013. Functional quality and antioxidant composition of selected tomato (Solanum lycopersicon L) cultivars grown in Northern India. LWT - Food Science and Technology 50 (1), 139-145. https://doi.org/10.1016/j.lwt.2012.06.013.

Martínez-Valverde, I., Periago, M.J., Provan, G., Chesson, A., 2002. Phenolic compounds, lycopene and antioxidant activity in commercial varieties of tomato (Lycopersicum esculentum). Journal of the Science of Food and Agriculture 82 (3), 323-330. https:// doi.org/10.1002/jsfa.1035.

Mohammed, A.E., Smit, I., Pawelzik, E., Keutgen, A.J., Horneburg, B., 2012. Organically grown tomato (Lycopersicon esculentum Mill.): Bioactive compounds in the fruit and infection with Phytophthora infestans. Journal of the Science of Food and Agriculture 92 (7), 1424-1431. https://doi.org/10.1002/jsfa.4720.

Moraru, C., Logendra, L., Lee, T.C., Janes, H., 2004. Characteristics of 10 processing tomato cultivars grown hydroponically for the NASA Advanced Life Support (ALS) Program. Journal of Food Composition and Analysis 17 (2), 141-154. https://doi.org/ 10.1016/j.jfca.2003.08.003.

Navarro-González, I., Periago, M.J., 2016. El tomate, ¿alimento saludable y/o funcional? Revista Española de Nutrición Humana Y Dietética 20 (4), 323-335 https://doi.org/ 10.14306/renhyd.20.4.208

Piombino, P., Sinesio, F., Moneta, E., Cammareri, M., Genovese, A., Lisanti, M.T. Grandillo, S., 2013. Investigating physicochemical, volatile and sensory parameters playing a positive or a negative role on tomato liking. Food Research International 50 (1), 409-419. https://doi.org/10.1016/j.foodres.2012.10.033.

Raffo, A., La Malfa, G., Fogliano, V., Maiani, G., Quaglia, G., 2006. Seasonal variations in antioxidant components of cherry tomatoes (Lycopersicon esculentum cv. Naomi F1). Journal of Food Composition and Analysis 19 (1), 11-19. https://doi.org/10.1016/j. jfca.2005.02.003.

Sánchez-Mata, M.C. Cámara-Hurtado, M., Díez-Marques, C., Torija-Isasa, M.E., 2000. Comparison of high-performance liquid chromatography and spectrofluorimetry for vitamin C analysis of green beans (Phaseolus vulgaris L.). European Food Research and Technology 210 (3), 220-225. https://doi.org/10.1007/PL00005516.

Sánchez-Moreno, C., Plaza, L., De-Ancos, B., Cano, M.P., 2003. Vitamin C, provitamin A carotenoid, and other carotenoids in high-pressurized orange juice during refrigerated storage. Journal of Agricultural and Food Chemistry 51 (3), 647-653. https://doi.org/ 10.1021/jf020795o.

Sánchez-Moreno, C., Plaza, L., De-Ancos, B., Cano, M.P., 2006. Nutritional characteri zation of commercial traditional pasteurized tomato juices: Carotenoids, vitamin C and radical-scavenging capacity. Food Chemistry 98 (4), 749-756. https://doi.org/10. 1016/j.foodchem.2005.07.015.

San-José, R., Sánchez-Mata, M.C., Cámara, M., Prohens, J., 2014. Eggplant fruit composition as affected by the cultivation environment and genetic constitution. Journal of the Science of Food and Agriculture 94 (13), 2774-2784. https://doi.org/10.1002/ jsfa.6623. 
Siddiqui, M.W., Ayala-Zavala, J.F., Dhua, R.S., 2015. Genotypic variation in tomatoes affecting processing and antioxidant attributes. Critical Reviews in Food Science and Nutrition 55, 1819-1835. https://doi.org/10.1080/10408398.2012.710278.

Slimestad, R., Verheul, M.J., 2009. Review of flavonoids and other phenolics from fruits of different tomato (Lycopersicon esculentum Mill.) cultivars. Journal of the Science of Food and Agriculture 89 (8), 1255-1270. https://doi.org/10.1002/jsfa.3605.

Toor, R.K., Savage, G.P., Lister, C.E., 2006. Seasonal variations in the antioxidant composition of greenhouse grown tomatoes. Journal of Food Composition and Analysis 19 (1), 1-10. https://doi.org/10.1016/j.jfca.2004.11.008.

Vallverdú-Queralt, A., Jauregui, O., Di-Lecce, G., Andrés-Lacueva, C., Lamuela-Raventos, R.M., 2011. Screening of the polyphenol content of tomato-based products through accurate-mass spectrometry (HPLC-ESI-QTOF). Food Chemistry 129 (3), 877-883. https: //doi.org/10.1016/j.foodchem.2011.05.038.

Vallverdú-Queralt, A., Jauregui, O., Medina-Remon, A., Lamuela-Raventos, R.M., 2012. Evaluation of a method to characterize the phenolic profile of organic and conven- tional tomatoes. Journal of Agricultural and Food Chemistry 60 (13), 3373-3380. https:// doi.org/10.1021/jf204702f.

Vallverdú-Queralt, A., Rinaldi-de-Alvarenga, J., Estruch, R., Lamuela-Raventos, R.M. 2013. Bioactive compounds present in the Mediterranean sofrito. Food Chemistry 141 (4), 3366-3372. https://doi.org/10.1016/j.foodchem.2013.06.032.

Verde-Méndez, C.M., Rodríguez-Rodríguez, E.M., Díaz-Romero, C., Sánchez-Mata, M.C., Matallana-González, M.C., Torija-Isasa, M.E., 2011. Vitamin C and organic acid contents in Spanish "Gazpacho" soup related to the vegetables used for its elaboration process. CyTA - Journal of Food 9 (1), 71-76. https://doi.org/10.1080/ 19476331003654393.

Weisburger, J.H., 2002. Lycopene and tomato products in health promotion. Experimental Biology and Medicine 227 (10), 924-927. https://doi.org/10.1177/ 153537020222701014.

Zapata, L.M., Gerard, L., Davies, C., Schvab, M.C., 2007. Study of antioxidants compounds and antioxidant activity in tomatoes. Ciencia, Docencia Y Tecnología 35, 173-193. 